\title{
A propósito de O Mal-Estar da Pós- Modernidade, de Zygmunt Bauman
}

\author{
Igor Zanoni Constant Carneiro Leão* \\ Demian Castro**
}

\begin{abstract}
Resumo: Este texto faz parte de uma discussão dos autores sobre a pós-modernidade, procurando apresentar seus principais fenômenos e sentidos a partir de notas críticas ao livro. O Mal-Estar da Pós-Modernidade, de Zygmunt Bauman, autor que é uma referência nessa área, por colocar em perspectiva a crise atual nas relações de trabalho, mobilidade social, cultura e espaço público. Nossa posição é que os principais fenômenos sociais, econômicos e culturais relativos ao problemático conceito de pós-modernidade ligam-se, sobretudo, à desregulamentação selvagem dos mercados de trabalho no capitalismo contemporâneo.
\end{abstract}

Palavras-chave: Pós-Modernidade, Cultura, Vida Contemporânea, Desenvolvimento Classificação JEL: O15; I31; Y30.

*Professor Associado da Universidade Federal do Paraná (UFPR).

** Professor Adjunto da Universidade Federal do Paraná (UFPR). 
Esta crítica pretende apresentar os principais sentidos em que o termo pós-modernidade é entendido no livro $O$ mal-estar da pós-modernidade, de Zygmunt Bauman, bem como tecer nossos comentários ao texto. A princípio uma moda em Ciências Sociais, a pós-modernidade hoje é um tema de pesquisa estudado por um conjunto grande de autores abrangendo diversas áreas. Z. Bauman, sociólogo polonês radicado na Inglaterra, é um dos mais férteis escritores nessa pesquisa, tendo diversos livros publicados no Brasil sobre essa temática. Nosso propósito é, a partir da leitura crítica do livro, fazer a crítica do, para nós problemático, conceito de pós-modernidade. Diversos autores recusam o conceito, mas aqui o aceitamos apenas para demarcar uma época de crise nas relações de sociabilidade e do espaço público, tal como indicado no livro que aqui relemos. Para nós, é fundamental que o conceito de pós-modernidade no autor esteja ligado especialmente à desregulamentação do mundo do trabalho na época da mundialização do capital.

O título do livro, como imediatamente se percebe, parodia o ensaio de Freud publicado em 1930 denominado, em inglês, Civilization and its Discontents e consagrado em português como O Mal-estar na Civilização. Note-se que o título procura seguir uma similitude com o título em português, na medida em que o original, em inglês, é Postmodernity and its discontents.

$\mathrm{Na}$ verdade Freud preferia o termo cultura ao termo civilização, indicando características do modernismo a partir de uma troca entre expressões plenas da libido por um esforço na construção da cultura moderna, que exigia uma dose apreciável de contenção ou repressão. Para Bauman, citando Freud, "A civilização se constrói sobre uma renúncia ao instinto" e impõe "grandes sacrifícios" à sexualidade e agressividade do homem. "O anseio de liberdade, portanto, é dirigido contra formas e exigências particulares da civilização ou contra a civilização como um todo". Trata-se de uma troca entre as possibilidades de gratificação por um quinhão de segurança, ao mesmo tempo em que há dificuldades inerentes à natureza da civilização que impedem qualquer tentativa de reforma.

A civilização ou cultura ou ainda modernidade troca sentidos com os termos beleza, limpeza ou ordem e consiste na compulsão à repetição de um regulamento estabelecido sem hesitação ou indecisão. Estão em jogo, aí, o princípio do prazer e o princípio da realidade. O mal-estar vem precisamente da limitação da liberdade de seguir as pulsões da libido em troca de mais segurança ante a ameaça inerente à fragilidade do corpo, a agressividade do mundo e dos vizinhos.

Para Bauman, a pós-modernidade se caracteriza, contudo, pela desregulamentação. Segundo o autor, a pós-modernidade pretende fundir a ordem limpa com o reclamo de prazer, privilegiando a liberdade individual como o maior predicado na contínua autocriação de um universo humano. Como enfatiza, os homens e as mulheres pós-modernas trocaram parte de sua segurança por mais felicidade, e os mal-estares da pós-modernidade provêm de uma liberdade na procura do prazer que tolera uma segurança individual pequena. 
A partir desse referencial, o livro de Bauman enfeixa um conjunto de textos mais ou menos independentes tentando descrever, ao mesmo tempo, características da cultura pós-moderna e dos mal-estares que ela implica. Inicia indicando a idéia ou a visão estética da pureza na idade moderna. A pureza é uma percep̧̧ão de ordem, caracterizada por um julgamento sobre o justo lugar das coisas e dos seres humanos. O oposto de pureza é o que está fora do lugar, o que caracteriza a impureza é a localização em uma ordem de coisas ideal. O interesse pela pureza está associado ao interesse pela higiene e à preocupação com a fragilidade da ordem e da hierarquia, como uma forma de ter uma razoável esperança de que hábitos e expectativas, bem como habilidades podem levar a uma boa organização do mundo. Muito freqüentemente, são outros seres humanos que são concebidos como um obstáculo para a organização do ambiente e para a ordem desejada. Esse sentido envolve uma definição do que são as pessoas do lugar e aquelas que são estranhas, incompatível com a renovação permanente de um mundo habitável e organizado.

A modernidade consistiu numa época em que a colocação em ordem dependeu do desmantelamento da ordem tradicional, implicando um permanente recomeço aos seres humanos, envolvendo sempre um perigo consistente com a instabilidade e inconstância, bem como da dificuldade de instalar uma ordem segura contra desafios que surgem. Não é casual que na época moderna muitas vezes se tenha buscado nada deixar ao acaso e erradicar os estranhos a partir de soluções totalitárias, como dá exemplo o nazismo e outras ideologias. O que caracteriza a época atual é uma indiferença crescente do Estado para com a tarefa de promover uma ordem singular e abrangente, ao mesmo tempo em que se percebe uma falta de interesse em organizar a desordem do mundo. Os homens pós-modernos apreciam novas experiências e preferem ser seduzidos pela aventura e ter opções abertas diante de qualquer fixação. Isso se relaciona com a figura dos seres humanos identificados principalmente como consumidores, sempre ávidos de novas sensações e experiências. Os novos impuros são aqueles redundantes para o mercado consumidor, exatamente porque são consumidores falhos.

A nosso ver as colocações de Bauman dão conta de um mundo crescentemente mercantilizado, no qual a produção da vida material foge das mãos dos seres humanos comuns diante da concentração da produção nas grandes empresas e do desemprego estrutural que marca a nossa época, bem como a desigualdade na renda que impede a fixação da maioria dos seres humanos a padrões de consumo identificadores de um status nobilitante. Realmente, o mundo se torna um lugar de produção de população excedente que precisa ser limpa como parecem pensar os partidos nacionalistas de direita na Europa e, por toda parte, o movimento neonazista com suas vítimas preferenciais entre negros, pobres e homossexuais, todos implicando uma desordem num mundo idealizado de padrões fixos de realização pessoal, marcada pela renda e pela preferência sexual. A conseqüência é a percepção de uma sujeira implícita nos incapazes de se inserir no mundo que não oferece chances para que eles possam se habilitar. A homofobia entra aí como um componente interessante na 
medida em que retrata um padrão tradicional e ideal de papéis sexuais como se qualquer subversão da ordem aí pudesse se generalizar e por em risco a ordem humana. Esse é o mal-estar vivido por aqueles que corroboram a exclusão social característica do capitalismo na atualidade e que reforçam esses mecanismos de exclusão.

Ainda para Bauman, os estranhos na sociedade pós-moderna são preferencialmente banidos do mundo ordeiro para guetos e proibições de contato chegando à aniquilação cultural e física dos estranhos. Essa discussão tem a ver com a construção da entidade do indivíduo, que na idade moderna era concebida como um projeto de vida erguido passo a passo de forma planejada dentro de um vínculo com a ordem social, também concebida como projeto. Uma característica do mundo pós-moderno é a velocidade com que profissões, ocupações e habilidades envelhecem mais depressa do que os seus titulares. Há um sentimento dominante de incerteza ligada, antes que à sorte e aos dons de uma pessoa, à futura configuração do mundo, a maneira correta de viver nele e como julgar erros e acertos. Essa é uma situação de incerteza permanente e irredutível.

Essa incerteza diz respeito a uma nova desordem do mundo com a desaparição do "Segundo Mundo" e a fragilização do "Terceiro Mundo" como uma força de oposição a ambos os blocos de poder e mesmo à noção de blocos. Em segundo lugar, fala-se da desregulamentação da ordem econômica, ou seja: "A desatada liberdade concedida ao capital e às finanças à custa de todas as outras liberdades, o despedaçamento das redes de segurança socialmente tecidas e societariamente sustentadas, e o repúdio a todas as razões que não econômicas, deram um novo impulso ao implacável processo de polarização, outrora detido (apenas temporariamente, como agora se percebe) pelas estruturas legais do Estado de bem-estar, dos direitos de negociação dos sindicatos, da legislação do trabalho e - numa escala global (embora, neste caso, de modo muito menos convincente) pelos primeiros efeitos dos órgãos internacionais encarregados da redistribuição do capital" (p.34).

A contrapartida dessa desregulamentação são os vários milhões de desabrigados, de expulsos do mercado de trabalho e dos que vivem abaixo da linha de pobreza mesmo na rica Europa, o sofrimento dos novos pobres, a identificação da pobreza com a humilhação e com a negação da liberdade do consumidor, identificada com a liberdade da humanidade. Os direitos humanos já não trazem implícita a aquisição do direito a um emprego, ao cuidado e à consideração por mérito ao passado. Em um mundo incerto, meio de vida, posição social, reconhecimento da utilidade e merecimento da auto-estima podem desaparecer imperceptivelmente da noite para o dia.

As outras redes de segurança como a família e a vizinhança também foram bastante enfraquecidas ou desintegradas. Os laços duradouros são quase inexistentes e as habilidades individuais e recursos inatos tendem a desaparecer diante das ferramentas tecnologicamente produzidas e mercantilizadas desagregando coletividades dependentes do mercado. Neste mundo indeterminável e maleável tudo pode acontecer e tudo pode ser feito, 
mas nada pode ser feito de uma vez por todas, os laços são dissimulados, as identidades se tornam máscaras sucessivamente usadas e se perde a história de vida. A construção da identidade é um processo inconcluso que gera o estranho.

A cidade moderna se divide em moradores de bairros bem arborizados trabalhando em escritórios fortificados no mundo dos negócios fortemente policiados, seguros nos carros recobertos de engenhocas de segurança e, por outro lado, em zonas habitadas por pessoas incapazes de escolher com quem elas se encontram e por quanto tempo, ou de pagar para ter suas escolhas respeitadas, pessoas sem poder num mundo vivido como uma armadilha sem saída, sem possibilidade de usar a liberdade do consumidor. Essa cisão da cidade coexiste com a visão conservadora de reforçamento de uma sociedade partida, sem uma cultura comum, sem ambições universalistas e assimilacionistas. A esquerda procura uma política de construção de comunidades, sem segurança quanto à tirania das pressões comunais, o despotismo da disciplina comunal, o narcisismo coletivo e outros males. Nesse quadro se inserem aqueles que pensam as relações raciais e étnicas independentemente do valor cultural da integração. O que está sendo polarizado não é apenas renda e riqueza, mas o direito à individualidade e à possibilidade de salvar os estranhos.

Esses estranhos não estão soltos sem identificação na sociedade. Seus números e sua identidade podem ser encontrados entre as décadas de oitenta e noventa na Europa, no crescimento acelerado de delitos penais, na reivindicação de renda suplementar e auxílio desemprego, na população de encarcerados e em toda a chamada indústria carcerária composta pela polícia, os advogados, os fornecedores de equipamento carcerário. Da mesma forma, no crescimento do número de exonerados, abandonados, excluídos da vida econômica e social. Como conseqüência, o aumento do sentimento popular de insegurança, fazendo com que seja sentido como perigoso andar à noite, por exemplo.

Esses fenômenos são associados pelo autor à "racionalização", ou seja, corte de empregos, a diminuição da força de trabalho ocupada, o fechamento de divisões e redução permanente de funcionários. A flexibilidade do capital faz com que ele ganhe, auxiliado pela informação moderna, domínio sobre surtos de crescimento que desaparecem subitamente. O estado de bem-estar que foi instituído como uma forma de seguro coletivo e um direito do cidadão transformou-se no fornecimento de donativos individuais e de caridade na medida em que cresce o número dos permanentemente desempregados, já não um grupo auxiliado pela rede de segurança da previdência a suportar o desafio da vida de modo temporário. Os dispositivos da previdência transformaram-se na marca dos incapazes e imprevidentes, na medida em que a indústria deixa de proporcionar trabalho, subsistência e segurança à maioria da população.

Ao mesmo tempo, aumenta-se o coro dos que se opõem a contribuir para os custos sociais e humanos da solvência econômica. Nessas condições, o seguro coletivo contra os riscos é privatizado e a sociedade, insegura sobre a sobrevivência de sua ordem, imagina-se uma "fortaleza sitiada". O Estado é incapaz de reproduzir uma ordem sistêmica e as forças de mercado sem regulamentação assumem a tarefa sem serem politicamente responsáveis nem 
capazes. Isso é coerente com uma sociedade à qual se apela, do ponto de vista individualizado do consumo e não da produção. O consumo torna-se a medida de uma vida bem sucedida, feliz e decente, passando uma ética sem normas, a não ser "saber aproveitar bem as cartas de que se dispõe".

$\mathrm{Na}$ medida em que há muitos jogadores sem cartas e fora do jogo, são redefinidos como "classes perigosas" e "consumidores falhos". São estes que alimentam a "indústria da prisão", nesta sociedade desregulamentada e privatizada, animada e dirigida pelo consumo. Nesse contexto a esmagadora maioria dos reclusos em um país como os Estados Unidos vêm da chamada "classe baixa", onde se armazenam os fracassados e rejeitados do consumo. A pena de morte se alarga assim como o controle judicial da sociedade e a publicidade favorável à eutanásia. Como diz o autor, "A radical privatização do destino humano acompanha aceleradamente a radical desregulamentação da indústria e das finanças", ao mesmo tempo em que criminaliza os que não podem escolher o seu destino.

Neste contexto, como mostra uma leitura atenta de autores como Emmanuel Lévinas e outros, a justiça e a preocupação com os direitos humanos são um apelo à humanidade e à caridade gerada pela ética que o Estado liberal não é capaz de consumar. Hans Jonas pensa na necessidade de um substituto para o imperativo categórico de Kant em uma forma como: Aja de modo de que os efeitos de sua ação sejam compatíveis com a permanência da genuína vida humana. Ao mesmo tempo, precisamos aplicar o "princípio da incerteza": deve-se dar maior atenção à profecia da destruição do que à profecia da bem-aventurança. É preciso uma ética de pessimismo sistemático para que os eventuais erros ocorram apenas por excesso de cautela. Pode-se também lembrar Jean-Paul Sartre quando afirmava que "não existem coisas como desastres naturais", mas apenas conseqüências de ações humanas indevidas e culposas.

É difícil pensar que o Estado poderia ser um agente que encampasse essa ética na medida em que a maioria dos principais atores nos mercados globais é muito maior que a maior parte dos Estados. É difícil dizer sob que condições a própria população pobre perceberá a condição humana como justa e correta desenvolvendo ações que signifiquem redenção, recuperação de perdas, reparação do dano, compensação pelos males sofridos, corrigindo a injustiça sistêmica como mostra a análise histórica de Barrington Moore Jr. Nessa situação policiam-se e incriminam-se os "pobres globais" - isto é, as áreas do mundo vítimas de pobreza endêmica - através de operações policiais, expedições militares, "pacificação em longo prazo de áreas incômodas", como uma contrapartida da atividade punitiva e vigilante do sistema carcerário interno. Trata-se de uma questão ética em que se deve pensar em dar aos Outros o mesmo grau de liberdade real e positiva que desfrutam os mais afortunados, transformando a justiça e a tolerância em real solidariedade.

Uma característica central da pós-modernidade é o nomadismo social dos indivíduos incapazes de fixar para si uma identidade e um lugar. O autor distingue, entre os nômades, aqueles que chegaram a um lugar mas este nunca pode ser considerado permanente. Os moradores mais antigos os odeiam e não 
têm residência segura. Estes são os arrivistas, enquanto os desafortunados são párias permanentemente desqualificados. Parece-nos que, sob essa forma, o autor dá conta da falta de mobilidade social nas sociedades pós-modernas, bem como da falta de identidade numa sociedade muito fluida que condena grande parte dos seus habitantes a guetos. Só resta aos indivíduos identificar-se com tribos que buscam uma tradição e uma comunidade onde se encontrem. Ao mesmo tempo a concentração da riqueza de forma crescente no topo da pirâmide social deixa intocada uma pequena parte da população para a qual, na verdade, a sociedade é um habitat permanentemente disponível. Nesta sociedade viceja, naturalmente, a heterofobia, a xenofobia e o racismo, bem como as práticas de separar, banir e exilar.

Nessa sociedade, "o eixo da estratégia de vida pós-moderna não é fazer a identidade deter-se - mas evitar que se fixe” (p.114). Isto porque ninguém pode investir numa realização de vida inteira quando os valores mudam permanentemente. Ninguém pode se preparar para a vocação da vida quando a aquisição penosa de habilidades pode deixar de apresentar interesse para o mercado. Assiste-se ao desaparecimento de profissões e empregos e mesmo compromissos pessoais e não profissionais tendem a se tornar estreitos e breves. Uma vez que não se controla o futuro, é bom não empenhá-lo. Assim, a sociedade possui personagens como turistas que nunca pertencem ao lugar que podem estar visitando, guardando sempre uma distância. Por outro lado, há os vagabundos para os quais não há nenhuma liberdade, autonomia ou independência, refugos ou restos do mundo dedicados aos que nele viajam como turistas. O importante é notar, sob essas metáforas, o movimento contínuo que a escala social e as identidades pessoais apresentam, a falta de lugar definido e a pequena liberdade de escolha da maioria dos estratos sociais.

Bauman, em outro capítulo, trata da arte pós-moderna, contrapondo-a ao modernismo. Este teria sido "um protesto contra promessas descumpridas e esperanças frustradas, mas também um testemunho da seriedade com que as promessas e esperanças foram tratadas... Os modernistas podiam declarar $e$ travar a guerra contra a realidade encontrada da vida moderna apenas porque aceitaram em tudo suas premissas: confiaram na natureza progressiva da história e acreditaram, assim, que o aparecimento do novo torna o existente, o legado e herdado redundantes, convertendo-os em relíquias e privando-os do direito de persistir" (p.123).

Na pós-modernidade, por sua vez, é difícil traçar uma linha divisória entre a arte de vanguarda e aquela que deve ser superada, já que as inovações não equivalem ao progresso, a novidade não se liga à revolução, e a publicidade, com sua cacofonia de signos, joga no lixo conceitos como pedantismo e vulgaridade. Ao mesmo tempo, a arte dos nossos dias foge da necessidade de retratar a realidade social, tem seus próprios procedimentos internos e perde a capacidade de representação de realidades sociais. Em outro capítulo, o autor continua a discutir a questão da arte para enfatizar que a arte contemporânea já não tem nada a ver com a representação, uma vez que ela não trabalha com idéia de uma verdade oculta e exterior que precisa ser captada pela obra de arte. 
Adentrando o terreno da filosofia, Bauman discute os conceitos de verdade e de certeza, concentrando-se na idéia de que, na atualidade, verdade simboliza uma determinada atitude que esperamos que os outros adotem e tem um sentido muito pragmático. Por outro lado, a noção de verdade pertence à retórica do poder, uma vez que se liga a relações de superioridade e inferioridade, de dominação e submissão, entre os detentores de crenças. Há uma pluralidade de verdades em uma cultura ocidental que, segundo Richard Rorty, está marcada pelo racismo, sexismo e imperialismo. Ao mesmo tempo, ela se apresenta como etnocêntrica, provinciana e intolerante, mas aspira a uma multiplicidade de diferentes espécies de pessoas com diferentes conceitos de Deus, verdade ou natureza das coisas. O autor retoma, assim, via o seu filósofo favorito, Rorty, a idéia de relativismo cultural associado a uma sociedade fragmentada, mas fortemente marcada por relações de poder.

Nesse sentido, o destino das artes é tornar a realidade suportável, a obra de ficção coloca em exibição o que a realidade tenta esconder, os mecanismos que retiram da agenda a separação entre verdade e falsidade e que tornam a busca de sentido irrelevante, improdutiva e cada vez menos atraente. Diante da ironia do mundo, a arte precisa tornar-se séria e defender essa seriedade que o mundo socialmente construído tornou ridículo. A arte, assim, através da imaginação, empatia e experimentação, está do lado dos solitários freqüentemente confusos, intérpretes pós-modernos dos conceitos de significado e de sentido. Assim, o autor quase chega a traçar um programa para a arte pós-moderna e para seus críticos. Sem buscar consenso como confirmação de sua validade, a ficção artística produz verdades destinadas a preencher a deficiência, na existência humana, criada por uma realidade que procura tornar redundante e irrelevante a busca de significado, e tornar essa busca indigna como objetivo dos esforços de uma vida.

Analisando o conceito de cultura, o autor o associa à experiência dos seres humanos em cujas mentes e conversas adquiriu uma forma comum. Ela era o reino da socialização, da educação, do ensino e do aprendizado, constituindose, como mostrou Michel Foucault, em fábricas de ordem, selecionando normas e padrões culturais de modo a atender as necessidades apresentadas e aperfeiçoando as regras existentes numa visão de conhecimento progressivo dos professores dessa cultura. Ela possuía, portanto, uma concepção hierárquica e a história humana é a narrativa da sua constituição. No presente, o termo cultura aparece agora como um produto da escolha arbitrária entre muitas possibilidades, e é necessário falar em culturas, no plural. Todavia, é preciso haver um sistema de valores centrais no ápice do sistema cultural, destinado a ordenar a ambivalência característica da pós-modernidade, mas é difícil pensar na cultura preenchendo essa função. Em uma época em que a noção de norma se torna nebulosa, quando, em primeiro lugar, os fenômenos culturais parecem ter mudado tanto que já não lhes cabe o antigo conceito de cultura, em segundo lugar quando ocorreram mudanças na nossa maneira de encarar e explorar o mundo e, em terceiro lugar, ocorreu um colapso da capacidade das noções ortodoxas de ordenar o conhecimento do mundo, o conceito de cultura como estabelecedora da 
ordem entra em crise como já mostrou a obra de Claude Lévi-Strauss.

Para o autor, uma boa metáfora para o novo paradigma capaz de captar a inquietação, adaptabilidade e a imprevisibilidade das atividades culturais é a noção de uma cooperativa de consumidores, capaz de fazer às vezes de uma espinha dorsal estabelecedora de ordem na cultura. O seu território, portanto, é o de um autogoverno. Esse conceito funciona junto com a noção de mercado, uma vez que os fenômenos culturais são sancionados num jogo de oferta e procura dos indivíduos. A nosso ver, essa é uma visão da possível criação cultural num mundo plural, mas que de alguma forma precisa ser ordenado em um sistema minimamente organizado de valores. O problema, aí, a nosso ver, é a ausência de como se processa a criação cultural na sociedade pós-moderna, uma vez que o autor não trabalha com os conceitos de indústria cultural, tão hierarquizada e importante para a difusão de valores e de um mínimo de consenso social, nem com as manifestações de um imenso leque de manifestações culturais cotidianas e populares que a um tempo devoram e transformam os produtos da indústria cultural. Há sempre um choque e um andar junto da ordem na cultura e as desordens ou outras ordens que se podem criar e manter.

O próximo capítulo do livro trata da sexualidade na cultura pós-moderna. Revisitando a História da Sexualidade, de Michel Foucault, Bauman relembra que em todas as suas manifestações, desde tempos imemoriais, o sexo serviu à articulação de novos mecanismos do poder e do controle social. Isso atingiu o controle da sexualidade infantil, esperando um maior controle sobre a própria criança. Da mesma forma, a família se tornou um terreno de aprendizado e disciplina para mulheres e crianças, dentro de uma reiterada inspeção, fiscalização e cuidado médico, ao mesmo tempo em que o homem demandava um espaço mais amplo que a casa familiar e retinha o direito ao sigilo e a um espaço privativo não controlado por outros membros da família. Com a chamada "segunda revolução sexual", em grande parte o "ninho familiar" enfraqueceu-se, dissociando o envolvimento romântico do amor erótico. Nesse processo, se o sexo na primeira revolução sexual servia como um pilar de construção da ordem, hoje serve antes a um processo de atomização dos indivíduos, e o sexo se transfere para o reino da coleção de experiências. Por outro lado, essa transformação se dá junto com o abandono do denso tecido de direitos adquiridos e deveres assumidos e as estruturas firmes do antigo casamento se tornam disfuncionais na medida em que nelas penetra uma lógica de tipo mercantil.

Essas importantes observações deixam de levar em conta fenômenos mais recentes do século XXI como o compromisso de um número crescente de jovens de manter a virgindade até o casamento, ao mesmo tempo em que cresce a demanda por retiros de casais nas igrejas e a própria igreja católica tem uma preocupação pastoral com os segundos casamentos e com a situação de pessoas que vivem juntas fora do casamento religioso. Parece que a lógica mercantil cansa um número crescente de pessoas pela sua instabilidade e falta de segurança emocional, mas é preciso estudar a extensão desse dado. Ele pode denotar uma busca de autonomia diante das exigências da cultura. É interessante notar que mesmo tendo desde João Paulo II uma postura mais 
conservadora, a Igreja Católica tem retomado espaço frente às novas seitas que lhe faziam concorrência, e suas atividades religiosas e sociais têm sido bastante buscadas ao menos no Brasil.

Em um capítulo dedicado à imortalidade na versão pós-moderna, o autor faz uma incursão sobre a questão da morte realçando as práticas sociais que acompanharam a morte ao longo do tempo. $\mathrm{Na}$ atualidade, deixando de lado a perene busca da imortalidade pela ciência, procura-se esconder de vista a morte daqueles próximos a própria pessoa e expulsá-la da memória, confinando os doentes terminais aos cuidados de profissionais e os velhos em guetos geriátricos e assim por diante. Aparentemente se busca fugir da morte e evitar o luto e isto se faz num processo de dessocialização da morte.

Finalmente, numa incursão sobre a religião, a ansiedade que acompanha a existência e que era atendida pela busca do transcendente tende a ser substituída por uma forma de vida humana em que os homens estão sozinhos para tratar de seus problemas. Essa ambição é a de fazer com que a liberdade e felicidade possam prevalecer sem apoios sobrenaturais numa ordem puramente humana. A religião continua como uma utilidade para muitos, crescendo dentro das igrejas as funções ancilares diante das dificuldades da vida, e em grande medida a religião funciona como um dos tipos de auto-ajuda longe de uma preocupação maior com os mistérios da existência e da morte.

Novamente, esse tratamento parece muito superficial, na medida em que muitos movimentos como a nova era buscaram uma renovação religiosa aberta ao mundo que, embora tenha concedido muito ao mercado, também provocou em muitos um conhecimento genuíno de outras experiências religiosas à medida que se conhecia melhor o mundo global. Não é por acaso que o budismo ou o taoísmo tenham uma penetração crescente no Ocidente. Por outro lado, crescem os movimentos pentecostais dentro do catolicismo ou das igrejas evangélicas, marcando-se por um rigor religioso inusitado para os padrões modernos.

Fazendo um balanço geral do livro, em primeiro lugar ele afirma na introdução que, passados sessenta e cinco anos da publicação de O Mal-Estar na Civilização, de Freud, a liberdade individual é o valor pelo qual todos os outros valores vieram a ser avaliados e a referência pela qual todas as normas e resoluções acima do indivíduo devem ser julgadas. Os ideais de beleza, pureza e ordem da modernidade devem agora ser buscados através da espontaneidade, do desejo e do esforço individuais. O livro de Bauman mostra precisamente o quanto essa liberdade individual é contida por fenômenos como a desestruturação do mercado de trabalho, a criminalização da pobreza, a mercantilização de importantes espaços culturais e emocionais como a arte e o amor. Nesse sentido ,sua história é de uma ordem que não pôde ser construída, na medida em que a maior parte dos atos da vida e de suas motivações foi desregulamentada, depois de ter sido concentrado, centralizado, globalizado e liberalizado o capitalismo global.

O livro de Bauman não trata especificamente da questão do Estado e da esfera pública nem tampouco de Economia Política e esses aspectos fazem falta para compreender melhor seus comentários sobre a fluidez da vida 
contemporânea e seu desamparo. Se o fizesse, talvez pudesse caracterizar a cultura pós-moderna como uma cultura paradoxalmente entrópica, que longe de produzir consensos e solidariedade, fragmenta ambos e gera um simulacro de civilização.

Seria por isso importante pensar se a pós-modernidade não é um neoconservadorismo, ou se há diferença entre essa cultura e o neoliberalismo, se ainda se pode falar e em que extensão de humanidade e direitos humanos ou de prerrogativas exclusivas do grande capital. O livro é da década de noventa e não apanha a crise econômica atual, cuja profundidade ainda não conhecemos. Talvez seja tempo de repensar os nexos materiais que unem os seres humanos e os separam e o grande mérito do livro de Bauman é, apesar de seus rodeios e de sua prolixidade, colocar alguma luz sobre esses nexos ou sobre o mal-estar que eles produzem.

Pode-se ainda acrescentar que, pensando no Brasil e em outras sociedades dependentes, após-modernidade instalou suas tenazes num tecido político e social fragilizado mas com ricas tradições regionais. É preciso pensar em como se apresenta o mal-estar brasileiro num país marcado historicamente pelo Estado fraco, sociedade fragmentada e heterogênea, sem uma cultura de solidariedade marcante, mas aberto aos ventos do capital global com poucos anteparos econômicos ou políticos. Pensamos que a situação do Brasil nesse aspecto é mais desastrosa que a da Europa, o que é uma obviedade lembrada pelo fato de Bauman escrever seu livro pensando na Europa. Recentemente foi criado no Brasil um instituto para medir e estudar o bem-estar da população. Onde andará esse bem-estar, dado o contexto que estamos observando?

Ainda é importante lembrar que Bauman é um sociólogo e não um psicanalista, o que torna seu livro um pouco defeituoso na medida em que as relações entre libido, bem-estar, poder, liberdade, têm uma história na clínica. Muitos fenômenos modernos como a agressão sexual a menores dentro da família parecem ter relação com a modificação nos papéis familiares e de poder entre homem e mulher. Entretanto, temas e conceitos básicos à psicanálise como o narcisismo, o individualismo e alienação são retomados como traços significativos da nossa cultura. A pós-modernidade faz do espelho um objeto necessário ao nosso reconhecimento e impede que nos encontremos.

Para essss e outras questões, o livro é um convite ao pensar, e um catálogo mais ou menos longo de temas que devem ser pensados. Pensamos que o ponto fundamental na obra de Bauman é dar conta de uma desmontagem acelerada da sociedade e da vida humana na atualidade, caracterizando uma "modernidade líquida". Como afirma Maria Laurinda Ribeiro de Souza, "Tudo é temporário; a modernidade é fluida - tal como os líquidos - e caracteriza-se pela incapacidade de manter a forma. A esse excesso de mobilidade, de informações, corresponde, no individuo, um sentimento agudo não só de insuficiência, mas também de banalização das experiências" (p. 73). Noutros termos, a vida parece como uma desmontagem dos lugares possíveis, no contorno sempre insatisfatório do próprio corpo, na fragilidade e frugalidade das relações amorosas em uma vida em permanente insegurança. Essa é a grande mensagem do seu livro. 
Igor Zanoni Constant Carneiro Leão, Demian Castro

\section{Referências}

Bauman, Z. (1925). O Mal Estar da Pós-Modernidade. Rio de Janeiro: Jorge Zahar Ed.

Souza, R. L. M. (2005). Violência.São Paulo: Casa do Psicólogo. 